\title{
Modernidade e modernismo: arte, técnica, trabalho
}

\author{
Marcos Fabris *
}

\begin{abstract}
Resumo
Em chave materialista histórica, este artigo pretende discutir as formulações equacionadas pelo crítico e poeta francês Charles Baudelaire para a arte moderna na Paris do século XIX e sua atualidade. Partindo sobretudo das considerações presentes em seu célebre ensaio $O$ pintor da vida moderna, pretende-se examinar o papel almejado para a arte política mais consequente, bem como os protagonistas que o desempenharão nas mais diversas formas de expressão artística - fotografia inclusa.
\end{abstract}

\section{Palavras-chave}

Estudos culturais. Modernidade. Modernismo. Charles Baudelaire. Crítica.

\begin{abstract}
A burguesia não pode existir sem revolucionar incessantemente os instrumentos de produção, por conseguinte, as relações de produção e, com isso, todas as relações sociais. [...] Essa subversão contínua da produção, esse abalo constante de todo o sistema social, essa agitação permanente e essa falta de segurança distinguem a época burguesa de todas as precedentes. Dissolvem-se todas as relações sociais antigas e cristalizadas, com seu cortejo de concepções e de idéias secularmente veneradas; as relações que as substituem tornam-se antiquadas antes de se consolidarem. Tudo o que era sólido e estável se desmancha no ar, tudo o que era sagrado é profanado e os homens são obrigados finalmente a encarar sem ilusões a sua posição social e as suas relações com os outros homens. (1998, p. 43)
\end{abstract}

\section{I}

A arte moderna, quando de seu surgimento "oficial" na Paris do século XIX, apresenta-se como expressão de novos arranjos sociais, decorrentes de transformações políticas e econômicas que se impunham sem precedentes na vida do período. Do ecletismo atemporal da pintura oficial da Monarquia de Julho, a arte do juste milieu, às produções que se opunham mais veementemente à arte acadêmica, as diversas práticas artísticas eram "modernas" uma vez que reagiam às condições impostas pela modernidade. Nos casos mais reacionários, celebravam na forma e no conteúdo a normatização vitoriosa do projeto burguês numa sociedade marcada pelo desenvolvimento da economia de mercado apoiada na ideologia da modernização

\footnotetext{
${ }^{*}$ Doutorando em Letras na FFLCH-USP.
} 
como símbolo de progresso, com seus decorrentes aguilhões: ação individual e aceleração na produção de mercadorias, cujo intuito era alimentar as engrenagens de tal sistema. A arte que vibrava neste comprimento de onda se colocava como um bem de consumo como outro qualquer, indissociavelmente ligada ao mercado do luxo. Quanto às práticas artísticas alternativas a essa, que pretendiam elas e que rumos tomariam para atingir seus objetivos?

\section{II}

Baudelaire, estimulado pela publicação dos ensaios de Diderot sobre os Salões (2008) em 1845, inicia sua crítica de arte esboçando um "sistema" para a produção artística mais politicamente progressista. Se a burguesia, impelida pela necessidade de novos mercados, liquida todas as relações precedentes que pareciam anteriormente solidificadas, almejando a expansão em escala global do sistema que a sustenta e promovendo, para o sucesso de sua empreitada, serialização, padronização e convertibilidade, tal movimento deverá, imperiosamente segundo Baudelaire, ser formalmente incorporado na fatura da obra de arte que se pensa como verdadeiramente moderna. A máxima de Diderot "Il faut être de son temps" deve, portanto, ser atualizada: o artista dos tempos modernos é aquele que produz uma arte de vanguarda que encontra sua centralidade na sensação e no sujeito, alvos primordiais de estímulos externos. Noutros termos, a natureza como compreendida por Diderot, ou seja, um objeto de prospeç̧ão, desteologizado e desnormatizado, um sistema racional com leis internas e auto-legislador, fora colonizado pelas estruturas do capital. Por outro lado, também as idéias de liberdade, igualdade e fraternidade provaram-se historicamente indissociáveis da idéia geral de progresso que, por sua vez, compreende a livre iniciativa, o primado da propriedade privada, a exploração da força de trabalho e a obtenção de lucros. Nos ideais das Luzes encontramos, assim, uma meia-verdade ou, se preferirmos, uma verdade com "pontos cegos"; no limite, um mito. O desenvolvimento histórico do Esclarecimento revelou o triunfo de seu mito, ou seja, aquele da racionalidade burguesa, desdobramento de sua lógica monetária (1995). Então, como buscar prospecção nesta natureza, sistema colonizado por uma lógica que, em nome da razão, articula e impõe relações irracionais? Se os ideais da Grande Revolução foram historicamente reprimidos, se a natureza de Diderot tornarase anacrônica, o que resta da operação de subtração do coletivo no projeto original é o sujeito na sua individualidade - notícia que já fora esboçada pela pintura francesa do período anterior: pensemos na dedicatória, na assinatura, na data e na explicitação das pinceladas do David de A morte de Marat, de 1793, todos indícios tanto do indivíduo retratado como do próprio artista individualizado. A partir da tradição que o precede, de Caravaggio a Hogarth, David chega nesta pintura a uma nova concepção de quadro histórico: "a história não é mais fato memorável e exemplar, tampouco drama ou episódio; é a lógica e, ao mesmo tempo, a moral dos acontecimentos." (2004, p. 44) Examinar a lógica e a moral dos acontecimentos modernos significa examinar sem ilusões o locus social e as relações entre os homens de então, indagando-se, como na formulação original de Diderot, sobre o status e o papel do "homem de bom senso" da época moderna. E ainda, a partir de concepções diderotianas sobre a arte: como fazer com que esta seja, em plena modernidade, 
"apreensível e interessante como um artigo de jornal"? Como executar uma obra que prime pela expressão de idéias, pelo juízo crítico e pela inteligência do real em tempos de tamanha retração política? Diderot, uma transição para a modernidade (um "protorealista"), lança as bases do programa que será retomado, desenvolvido e atualizado por Baudelaire.

Vemos, deste modo, que para o crítico e poeta francês, ser de seu tempo significa investigar tais questões, buscando a inteligência desnormatizada do real, a partir do sujeito, em chave de reconstrução materialista da História. Para tanto, o compromisso com a apreensão da realidade vincula-se agora diretamente à explicitação dos conflitos de classes (a experiência do choque moderno) e ao posicionamento político do artista frente a eles. Nestes termos, o interesse deste tipo de produção artística reside, sobretudo, no confronto do artista com as práticas modernas relativas à vida na cidade e as recentes formas de sociabilidade ali criadas pelas novas configurações arquitetônicas e urbanísticas, expressões da configuração contemporânea do trabalho que, por sua vez, é produto derivado do contínuo desenvolvimento do capital. A questão que se põe perante o artista é aquela da representação deste mundo, que combina efemeridade, trivialidade e tragicidade. Trata-se de figurar o amálgama de aspectos destrutivos que caracterizam um período no qual:

\begin{abstract}
o burguês torna-se autoconfiante, impertinente, arrogante, e imagina que pode esconder a humildade de suas origens e a constituição híbrida da nova sociedade elegante, na qual o demi-monde, as atrizes e os estrangeiros desempenham um papel sem precedentes, mediante meras exterioridades. A dissolução do ancien régime entra na fase final e, com o desaparecimento dos últimos representantes da velha e boa sociedade, a cultura francesa passa por uma crise mais séria do que quando recebeu seu primeiro choque violento. Em arte, [...] o mau gosto jamais ditara a moda de forma tão preponderante quanto agora. Para os novos-ricos, suficientemente abastados para querer brilhar mas não suficientemente velhos para brilhar sem ostentação, nada é dispendioso ou pomposo demais. Não discriminam na escolha de meios, no uso de materiais genuínos ou falsos, nem nos estilos que adotam e misturam. Renascença e barroco significam para eles, meios para um fim, tanto quanto o são o mármore e o ônix, o cetim e a seda, o espelho e o cristal. Imitam palácios romanos e castelos do Loire, átrios pompeanos, salões barrocos, os móveis dos marceneiros de Luís XV e as tapeçarias de Luís XVI. Paris adquire um novo esplendor, um novo ar metropolitano. Sua grandeza, entretanto, é com frequência apenas uma aparência exterior, os materiais pretensiosos não passam, na maioria das vezes, de substitutos: o mármore é apenas estuque, a pedra apenas reboco; as magníficas fachadas são meramente chapeadas, a rica decoração é inorgânica e amorfa. Um elemento inidôneo introduz-se na arquitetura, correspondendo à estrutura parvenu da sociedade vigente. Paris torna-se de novo a capital da Europa, não, porém, como antes, o centro de arte e cultura, mas a metrópole do mundo da diversão, a cidade da ópera, da opereta, do balé, dos bulevares, restaurantes, das lojas de departamentos, das exposições universais e dos prazeres baratos e prontos para consumo. $(1995$, p. $788-789)$
\end{abstract}

\title{
III
}

Em seu ensaio $A$ arte filosófica (1980), Baudelaire sugere uma síntese entre romantismo (Delacroix) e realismo (Courbet, Corot) que estabeleça relações concomitantes entre objeto e sujeito, mundo exterior e o próprio artista. A esta síntese artística caberia a tarefa de figurar, ao contrário da plataforma da École de Barbizon, a 
vida no ambiente urbano e o efêmero nele contido - afinal, não eram nas cidades, e sobretudo na moderna Paris, que se corporificavam mais nitidamente as relações inter-constitutivas entre avanço e retrocesso, que incessantemente se consolidam e se degradam numa espécie de "presente sem fim"? Ao exigir que a pintura adote a tríade vivência do instante - não um qualquer, mas aquele com dimensão reflexiva, que se manifesta no contingente e que o ultrapassa, revelando a essência do que the é duradouro -, sensação e ênfase na pincelada marcada, Baudelaire edifica os pilares do que será a pintura da vida moderna.

O pintor da vida moderna (1980), corolário da reflexão iniciada desde O Salão de 1845, articulará os princípios de refundação da pintura que pretende dar notícia da espetacularização desta vida moderna, codificada na/pela nova linguagem visual. Trata-se assim do encontro entre pintura moderna e um mito da modernidade, a saber, o da modernização, e do confronto com a insuficiência da imagística anterior na figuração de determinados estados e movimentos, da necessidade que tiveram os novos modos de representação de conceber categorias artístico-cognitivas distintas das precedentes, partindo da expressão empírica da realidade (aparência), porém buscando, na dissolução da imediaticidade do objeto, compreendê-lo como expressão coagulada de processos materiais (essência). Esta pintura não almejaria "gerar" objetos, mas, bem ao contrário, "reconstituí-los" a partir da narrativa de suas determinações materiais e históricas. Em outros termos, apropriando-se de uma gramática da aparência que tenciona falar no e do novo idioma que se configura socialmente - e com regras bastantes rígidas prescritas pela "norma culta" burguesa , a nova pintura deveria fazer uso de determinadas categorias, mais especificamente aquelas do espetáculo e da classe, como "formas específicas de visualização" (2004, p. 26) para a compreensão (e figuração) da ficção convincente que se tornara Paris. A partir de então, toda e qualquer permanência acrítica na "língua" realista-ilusionista configurará modos mais ou menos conservadores de representação da realidade.

Além do elogio ao tempo presente como objeto de cognição e ao movimento rápido que capta suas diversas expressões na vida urbana, Baudelaire valoriza o "homem do mundo" como o arauto do universo contemporâneo (por oposição ao artista profissional, o pintor de ofício, ou, numa comparação ácida com aqueles que se pautam pela engessada normatização acadêmica, o "servo da gleba"). A arte moderna será a narrativa deste mundo por este homem. Entra em cena a figura paradigmática de Constantin Guys, o artista-repórter eleito por Baudelaire como aquele que através de sua prática artística extrai o eterno do transitório na fantasmagoria da cidade. Através da observação direta da realidade e do olhar seletivo que deita sobre a tradição que o precede, Guys sintetiza suas impressões sobre os costumes, a moda e a guerra numa formulação artística que aliava a memória sintética de sua hora histórica à rapidez de execução das obras.

Baudelaire (re)cria a figura de Constantin Guys como exemplo máximo deste artista que narra a experiência moderna, aquela do embate, e em âmbito transnacional: 
A Bulgária, a Turquia, a Criméia e a Espanha foram grandes festas para os olhos de C. G., ou melhor, para os olhos do artista imaginário que convencionamos chamar de C. G.; pois lembro-me de vez em quando que prometi a mim mesmo, para tranquilizar ainda mais sua modéstia, supor que ele não existe. (1980, p. 801 meus grifos)

Ora, se aqui o literato encontra o crítico e explicita que Constantin Guys não existe tal como figura humana mas como desiderato (2002), podemos supor que o pintor ou artista da vida moderna são, plasmados a partir da "personagem" Guys, todos os que cumprem (e atualizam) o programa baudelairiano, no qual contemporaneidade e instantaneidade encontram-se indissociavelmente ligadas. Se, a partir destes dois elementos, tal programa insiste que ao representar o fragmento o pintor da vida moderna estabeleça relações entre a parte e o todo, "fabricando imagens, montando cenários e pondo o real como artifício e não como natureza" (2007, p. 12), não teriam Baudelaire, seu personagem Guys e todos os seus sucessores, expandido o repertório das forças produtivas até então disponíveis? Não teriam eles refundado a pintura ( $e$, como pretendo demonstrar adiante, a fotografia) e seu próprio conceito, agora essencialmente articulada nos termos de em um sistema fotográfico (e, no limite, cinematográfico), para, deste modo, re-atualizar as bases de uma nova etapa da estética realista? Escoimadas as restrições artísticas, a concepção do que era arte, e mais especificamente do que deveria ser uma arte realista, dilata-se estética e politicamente ${ }^{1}$.

Aqui, Realismo não equivale mais ao perfil fiel da realidade imediatamente visível, mas à representação de um conjunto específico de situações a partir de um determinado ponto de vista, liberto, naturalmente, dos grilhões da norma acadêmica. O caráter realista desta arte almeja desnudar as diversas redes de relações causais na modernidade, explicitando o ponto de vista dominante como aquele do dominador, para tanto adotando na prática artística o ponto de vista da classe que concebeu as soluções mais abrangentes para as questões candentes que afligiam a sociedade moderna - aquele do proletariado (1978). O Realismo é, assim, concebido primordialmente como um compromisso com a verdade, no qual "verdade" equivale a posicionamento do artista em relação às lutas de classes num determinado tempo e espaço históricos. Trata-se, sobretudo, de um uso profundamente político e histórico do conceito de realismo (e de verdade), que determinará os procedimentos estéticos mais indicados a serem utilizados pelo artista, segundo sua avaliação do estado, da natureza e das possibilidades do confronto com seu objeto em cifra histórica. Portanto o Realismo não é, de modo algum, um receituário estético ou artístico definido a priori.

A notícia da reorganização das forças pictóricas da pintura francesa é corolário do desenvolvimento histórico e materialista da França revolucionária do século XVIII; o rumo à concepção e organização de um sistema fotográfico para as artes visuais mais progressistas fora apontado pelo David revolucionário de O sermão do Jeu de Paume (1791-92) e do já citado $A$ morte de Marat. Neles, a expressão do desejo e necessidade de um "Eros realista e não aristocrático" se materializa na nova economia do visível: a pintura posta como um atelier fotográfico móvel, capaz de executar a obra com rapidez, a busca de temas e assuntos nas ruas, não nos tradicionais lugares de culto - o palácio ou a Igreja - e o abandono do léxico neo-clássico para fazê-lo, com apelo aos signos que invocam instantaneidade e a combinação desta nova entidade à historicidade do presente. A esse respeito, ver: MARTINS, L. R. $O$ hemiciclo: imagem da forma-Nação. In: Crítica marxista. São Paulo: UNESP, 2009, n. 29. 
Como Brecht, outro grande proponente de uma nova concepção de Realismo, viria dizer:

Não devemos conceber o Realismo a partir de certas obras existentes. Ao contrário, deve-se empregar todos os procedimentos, os antigos e os novos, os consagrados e os inéditos, aqueles tomados emprestados da arte e aqueles que vêm de outras fontes para, assim, pôr nas mãos dos homens a realidade viva sob uma forma que se possa dominar [in such a way that it can be mastered]. [...] Realista significa: desvendar a causalidade das relações sociais [...]. (1978, p. 109).

Este Realismo alarga ao infinito o modo operatório da obra de arte pois apregoa um regime "anarquista" para as artes, ou seja, ausência de restrições de qualquer natureza, de modo que o artista possa expressar livremente sua insatisfação com seu tempo a partir da honestidade que terá com a matéria social que encontra diante de si, absorvendo-a criticamente na fatura da obra de arte para esclarecimento dos contextos sócio-históricos que a engendraram (muitíssimo distinto do uso espúrio que faria o pós-modernismo da "liberdade" que apregoa).

Nestes termos, o artista deve ser, como exigira Baudelaire, um "homem do mundo". E quem é o homem do mundo moderno senão o trabalhador! A "genialidade" do artista como "criatura elevada", dotada de saber ou dom especial, ímpar, deve ser substituída pela prosaica condição de um trabalhador que domina uma determinada técnica que, ao contrário do dom (ou mesmo do "estilo", a inimitável presença de um indivíduo único), pode ser transmitida, aperfeiçoada e disponibilizada; este artista assemelha-se ao trabalhador na linha de montagem. Porém, diferentemente deste, 0 artista que é consciente de sua condição de trabalhador ligado a relações de produção específicas conta com a possibilidade de engajar-se em trabalho não alienado: ao contrário do trabalhador que alcança pseudo-liberdade para vender sua força de trabalho num mercado que, na verdade, pressupõe forças sociais assimétricas, ele pode superar dialeticamente sua função tradicional como excrescência da modernização se levar a técnica que domina até os limites extremos do possível, implodindo suas fronteiras de tal modo a refundar o próprio conceito de arte e do fazer artístico, atingindo deste modo, mesmo que em termos ainda não efetivos, uma vitória simbólica, em conformidade com uma (sempre) nova noção de Realismo: uma arte processual, fundada numa consciência fenomênica e materialista, que deve priorizar a explicitação crítica da fabricação e dos seus nexos, ou seja, a exposição da natureza do próprio trabalho².

\section{IV}

É verdade que a experiência revolucionária no campo da arte somente se completa totalmente quando efetivadas as alterações das relações de produção, ou seja, no momento em que os trabalhadores detiverem a posse dos meios de produção.

2 Faço aqui uso da idéia de um novo realismo desenvolvido a partir da idéia de montagem e serialização na obra de Cézanne - procedimentos que poderiam ser levados a extremos pelos meios reprodutíveis, fotografia e cinema. 
Nos termos artísticos, isto significa anular a distinção entre fruição e produção artística, ou, se preferirmos, entre autores e produtores. Ao descrever o papel do escritor progressista, Walter Benjamin dá a chave para a compreensão da tarefa de todos os artistas que reconhecem sua autonomia artística - no âmbito das lutas de classes e a serviço do proletariado:

Um escritor que não ensina outros escritores não ensina ninguém. O caráter modelar da produção é, portanto, decisivo: em primeiro lugar, precisa colocar à disposição deles um aparelho mais perfeito. Esse aparelho é tanto melhor quanto mais conduz consumidores à esfera da produção, ou seja, quanto maior for sua capacidade de transformar em colaboradores os leitores ou espectadores. (1993, p. 132)

Nas artes visuais, o "aparelho" mais perfeito posto à disposição das massas foi, até então, a câmera fotográfica. O novo meio reprodutível guarda em si a possibilidade de desestimular a separação entre artista e público, ampliando mais democraticamente o acesso à técnica e ao repertório da produção visual artística. Os possíveis procedimentos de distanciamento e de "iluminação profana" que comportam as artes fotográficas tornam ainda mais eficiente o campo de treinamento que pretende figurar a experiência do choque moderno. Acessibilidade, rapidez na execução, economia de meios e de energia para os trabalhadores-artistas: esta combinação permite desnormatizar e re-treinar o olhar para, através das inúmeras possibilidades de montagem que o meio permite, desembotar a percepção do homem moderno. Contemporaneidade e instantaneidade encontram-se ainda mais intimamente associadas que outrora. A explicitação de um ponto de vista construído, marca de um lugar social e portanto de classe, efetiva a crítica à modernização. A decrepitude da grande arte é finalmente consumada: ela se "degrada" em técnica.

\section{Referências:}

ADORNO, T. e HORKHEIMER, M. Dialectic of Enlightenment. Londres e Nova York: Verso, 1995.

ARGAN, G. C. Arte moderna - do Iluminismo aos movimentos contemporâneos. São Paulo: Companhia das letras, 2004.

BAUDELAIRE, C. Fuvres complètes. Paris: Éditions Robert Laffont, 1980.

\footnotetext{
${ }^{3} \mathrm{O}$ conceito é cunhado por Walter Benjamin para descrever o processo da superação religiosa que alcançaram os surrealistas. Trata-se da própria idéia de pensamento crítico, de inspiração materialista, ligada ao prazer da intoxicação da descoberta e da compreensão de novas formas possíveis, desvinculadas dos modos de representação ligados à lógica e racionalidade burguesas, capazes de apreenderem determinados estágios sociais. As artes fotográficas guardam relações de interesse com procedimentos típicos surrealistas, mesmo antes que estes se configurem como projeto artístico. O caso Atget é, como veremos adiante, paradigmático de um artista surrealista avant la lettre. Cf. BENJAMIN, W. O surrealismo - o último instantâneo da inteligência européia. In Obras escolhidas - magia e técnica, arte e política. op. cit.
} 
BENJAMIN, W. Obras escolhidas - magia e técnica, arte e política. São Paulo: Brasiliense, 1993.

CLARK, T. J. A pintura da vida moderna - Paris na arte de Manet e de seus seguidores. São Paulo: Companhia das Letras, 2004.

DIDEROT, D. Salons. Paris: Éditions Gallimard, 2008.

HAUSER, A. História social da arte e da literatura. São Paulo: Martins Fontes, 1995.

MARTINS, L. R. Manet - uma mulher de negócios, um almoço no parque e um bar. Rio de Janeiro: Jorge Zahar Editor, 2007.

. O hemiciclo: imagem da forma-Nação. In Crítica marxista. São Paulo: Fundação Editora UNESP, 2009, n. 29.

MARX, K.; ENGELS, F. Manifesto comunista. São Paulo: Boitempo Editorial, 1998.

PICHOIS, C. Baudelaire et Constantin Guys. In Constantin Guys - Fleurs du Mal. Paris: Éditions des musées de la Ville de Paris, 2002.

WILLET, J. (org.) The popular and the realistic. In Brecht on theatre - the development of an aesthetic. Londres: Methuen, 1978.

\section{Title}

Modernity and Modernism: Art, Technique, Work

\section{Abstract}

Based on the perspective of the Historical Materialism, the present paper discusses those formulations by the French poet Charles Baudelaire for modern art in the nineteenth century Paris and its actuality. With a focus on those considerations present in the famous The Painter of Modern Life, an analysis is made on the desired role for a more consequent political art, as well as the protagonists who will carry on such an art with a variety of artistic expression, including photography.

\section{Keywords}

Cultural Studies, Modernity, Modernism, Charles Baudelaire, Criticism.

Recebido em 25.04.2011. Aprovado em 11.07.2011. 